\title{
DIVERSIFICAÇÃO PRODUTIVA EM ÁREAS CULTIVADAS COM TABACO: UMA EXPERIÊNCIA NO MUNICÍPIO DE ARROIO DO PADRE/RS COM SEMENTES CRIOULAS E VARIETAIS
}

\section{Germano Ehlert Pollnow}

Universidade Federal de Pelotas - Núcleo de Pesquisa e Extensão em Agroecologia e Políticas Públicas para Agricultura Familiar (NUPEAR/UFPel) Pelotas - Rio Grande do Sul - Brasil

E-mail: germano.ep@outlook.com

Orcid: https://orcid.org/0000-0002-2742-8758

\section{Roni Carlos Bonow}

Fundação Luterana de Diaconia/Centro de Apoio e Promoção da Agroecologia São Lourenço do Sul, Rio Grande do Sul, Brasil

E-mail: ronibonow@gmail.com

Orcid: https://orcid.org/0000-0001-5230-5488

\section{Marcio Marcelo Garcia Morales}

Fundação Luterana de Diaconia/Centro de Apoio e Promoção da Agroecologia Pelotas, Rio Grande do Sul, Brasil

E-mail: marciomorales@gmail.com

Orcid: https://orcid.org/0000-0002-7333-3987

\section{Fábio André Mayer}

Fundação Luterana de Diaconia/Centro de Apoio e Promoção da Agroecologia Pelotas, Rio Grande do Sul, Brasil

E-mail: fanmayer@yahoo.com.br

Orcid: https://orcid.org/0000-0002-9720-4119

Recebido em 24/06/2020 aprovado em 15/03/2021

DOI: http://dx.doi.org/10.5380/guaju.v7i1.74691

\section{Resumo}

Este trabalho tem por objetivo apresentar a experiência que vem sendo desenvolvida no município gaúcho de Arroio do Padre, no âmbito do projeto de assistência técnica e extensão rural intitulado "O Terceiro passo na diversificação produtiva, econômica e sustentável em áreas cultivadas com tabaco na Zona Sul do Estado/RS", contratado pela Agência Nacional de Assistência Técnica e Extensão Rural (ANATER) e levado a cabo pelo Centro de Apoio e Promoção da Agroecologia (CAPA/Núcleo Pelotas), filial da Fundação Luterana de Diaconia (FLD). A ênfase do trabalho está na valorização da agrobiodiversidade local através da extensão rural. $\mathrm{Na}$ execução do projeto são realizadas atividades técnicas individuais e coletivas 
junto ao público beneficiário. Com as atividades já realizadas, foi possível distribuir, promover a troca e/ou comercialização de sementes e mudas crioulas e varietais de milho, feijão, cebola, batata-doce e abacaxi para cerca de 80 famílias. Assim, para a conservação da agrobiodiversidade, é importante mencionar o papel das entidades prestadoras de serviços de ATER e salientar a importância das pessoas, num contexto de valorização da sustentabilidade e da agroecologia.

Palavras-chave: Agricultura Familiar; Agroecologia; ATER; Extensão Rural; Sustentabilidade.

\title{
Productive Diversification in Tabacco Growing Areas: An Experience in the Municipality of Arroio do Padre/RS With Seeds Creoles and Varietals
}

\begin{abstract}
This work aims to present the experience that has been developed in the city of Arroio do Padre, Rio Grande do Sul, in the scope of the technical assistance and rural extension project entitled "The Third step in the productive, economic and sustainable diversification in areas cultivated with tobacco in the South Zone do Estado/RS", hired by the Agência Nacional de Assistência Técnica e Extensão Rural (ANATER) and carried out by the Centro de Apoio e Promoção da Agroeologia (CAPA/Núcleo Pelotas), a branch of the Fundação Luterana de Diaconia (FLD). The work's emphasis is on valuing local agrobiodiversity through rural extension. In the execution of the project, individual and collective technical activities are carried out with the beneficiary public. With the activities already carried out, it was possible to distribute, promote the exchange, and/ or creole seeds and seedlings and corn, beans, onions, sweet potatoes, and pineapples commercialization to around 80 families. Thus, for agrobiodiversity conservation, it is significant to mention the role of ATER service providers, and emphasize the importance of people in valuing sustainability and agroecology context.

Keywords: Agroecology; ATER; Family Farming; Rural Extension; Sustainability.
\end{abstract}




\section{Introdução}

O Centro de Apoio e Promoção da Agroecologia (CAPA) foi criado em 1978, como um serviço da Igreja Evangélica de Confissão Luterana no Brasil (IECLB) ${ }^{1}$ para auxiliar agricultoras e agricultores familiares na permanência no campo, com qualidade de vida, autonomia, protagonismo e justiça social. O trabalho é realizado através da assessoria técnica na produção de alimentos, do resgate histórico-cultural, da inserção de agricultoras e agricultores nas discussões de políticas públicas, buscando por meio da agroecologia, assegurar uma vida mais digna para as famílias agricultoras e oferecer alimentos mais saudáveis para famílias consumidoras (CAPA, 2019a).

A instituição possui cinco núcleos com atuação na região sul do Brasil: no Rio Grande do Sul, em Pelotas; Santa Cruz do Sul e Erechim (que atua também em Santa Catarina); e no Paraná, em Verê e Marechal Cândido Rondon. Atualmente, juridicamente, os cinco núcleos são filiais da Fundação Luterana de Diaconia (FLD). O CAPA Núcleo Pelotas, objeto deste trabalho, atua no território zona sul do RS, conforme demonstra a figura a seguir (Fig. 1). A instituição possui uma histórica caminhada de motivação, apoio e assessoria às organizações da agricultura familiar. Possui reconhecimento, credibilidade e premiações como entidade de referência em agroecologia, organização social e desenvolvimento rural sustentável (CAPA, 2019a).

10 CAPA trabalha com todos os credos e crenças e valoriza a cultura de povos e comunidades tradicionais. Fundamenta-se na disseminação de práticas econômica e ecologicamente sustentáveis, entre famílias produtoras rurais, considerando os princípios do protagonismo, associativismo, solidariedade, sustentabilidade e respeito ao meio ambiente. 
Figura 1: Representação da área geográfica de atuação do CAPA Núcleo Pelotas.

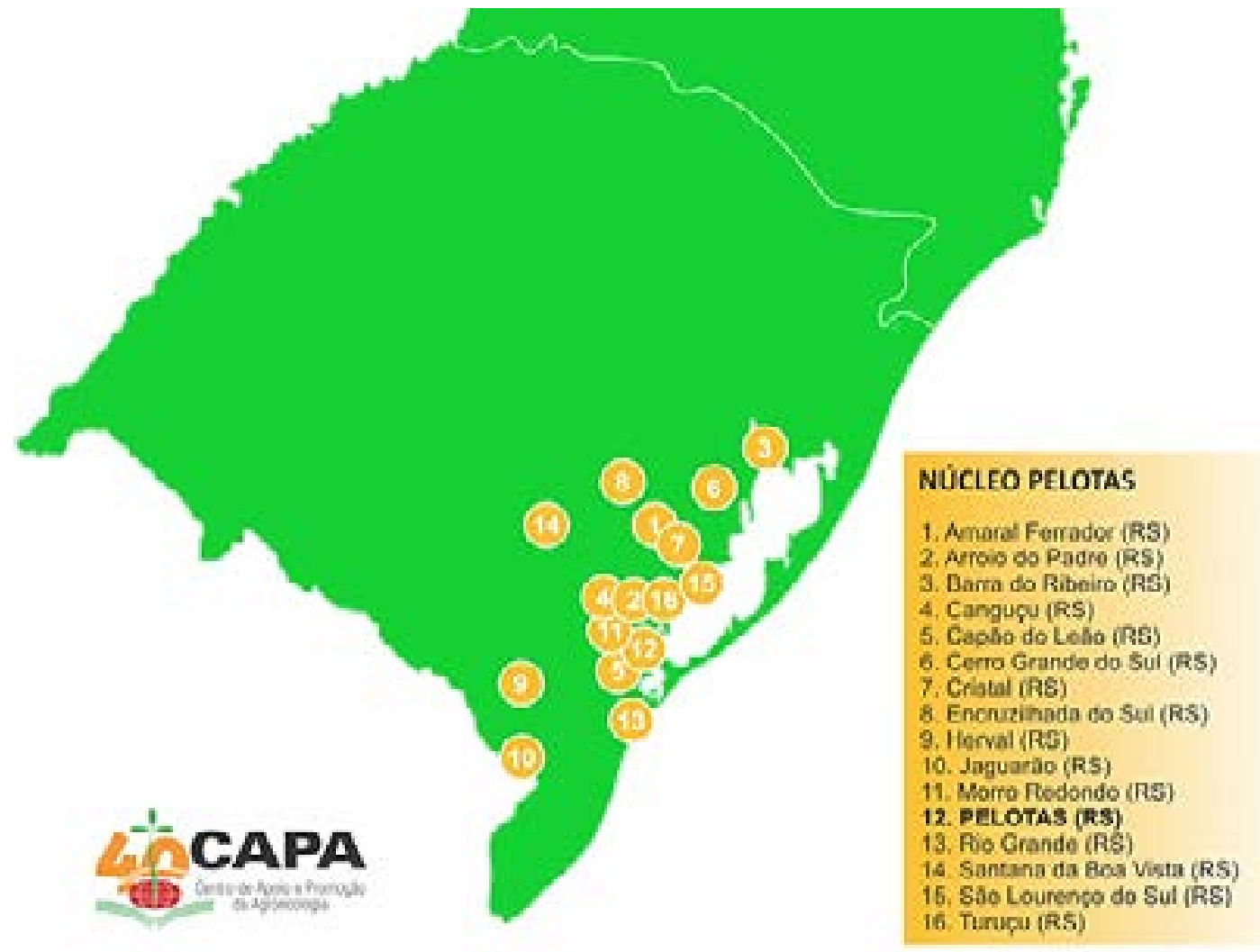

Fonte: Adaptado de CAPA (2019b).

Desde 2012, o CAPA Pelotas vem desenvolvendo atividades de Assistência Técnica e Extensão Rural (ATER) com foco na diversificação produtiva, atividades estas vinculadas ao Plano Nacional de Diversificação em Áreas Cultivadas com Tabaco (PNDACT), o qual, por sua vez, está ligado à Convenção Quadro para Controle do Tabaco (CQCT). O primeiro projeto (Contrato 11/2012 MDA SAF/DATER) envolveu o atendimento a 960 famílias de sete municípios ${ }^{2}$ durante os anos de 2012 e 2013. Em um segundo projeto (Contrato 151/2013 MDA SAF/DATER), durante os anos de 2014 a 2016, o trabalho se deu com 1.200 famílias dos mesmos municípios.

Mais recentemente, em agosto de 2018, a Agência Nacional de Assistência Técnica e Extensão Rural (ANATER) publicou o edital de Chamada Pública no 07/2018, visando a contratação de entidades para execução de serviços de ATER destinados a agricultoras e agricultores familiares de municípios produtores de tabaco no âmbito do PNDACT na região Sul do Brasil (ANATER, 2018). O CAPA concorreu ao edital com o projeto intitulado"O Terceiro passo na diversificação produtiva, econômica e sustentável em áreas cultivadas com tabaco

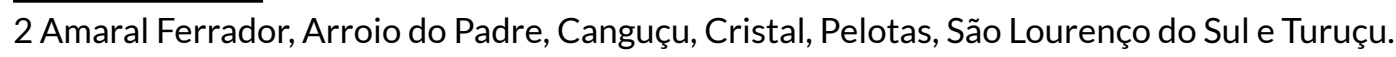


na Zona Sul do Estado/RS", sagrando-se o projeto vencedor na referida região. Assim, foi firmado entre CAPA e ANATER o contrato no 93/2018.

O público beneficiário deste projeto é composto por 960 famílias agricultoras e produtoras de tabaco nos municípios de Amaral Ferrador, Arroio do Padre, Canguçu, Pelotas, São Lourenço do Sul e Turuçu. A execução das atividades e metas se deu a partir de janeiro de 2019, com vigência do contrato até dezembro de 2020.

É importante mencionar que, apesar do foco desse serviço estar centrado na diversificação produtiva, busca-se a construção de uma ATER com base na agroecologia, com equidade de gênero, fortalecimento das organizações sociais e valorização da agrobiodiversidade da região.

Dessa forma, o objetivo da presente sistematização é apresentar a experiência que vem sendo desenvolvida no âmbito do referido projeto de ATER no município de Arroio do Padre, com ênfase no trabalho de valorização da agrobiodiversidade local, envolvendo sementes e mudas crioulas e varietais. Quiçá esta sistematização possa conduzir a reflexões teóricas e aprimorar experiências práticas, além de motivar trabalhos - teóricos e práticos sobre agrobiodiversidade, sustentabilidade, agroecologia e extensão rural.

Antes de avançar para a descrição da experiência e para os resultados alcançados, convém antes apresentar a metodologia utilizada que alicerçou a elaboração desta sistematização.

\section{Metodologia}

Na construção deste trabalho, foram utilizados os preceitos de Holliday (2006), o qual define a sistematização de experiências como uma

\footnotetext{
interpretação crítica de uma ou várias experiências que, a partir de seu ordenamento e reconstrução, descobre ou explicita a lógica do processo vivido, os fatores que intervieram no dito processo, como se relacionaram entre si e porque o fizeram desse modo (HOLLIDAY, 2006, p. 24).
}

O mesmo autor entende que a sistematização de experiências "trata-se não só de entender situações, processos ou estruturas sociais mas também, no fundamental, conhecer como se produzem novas situações e processos que podem incidir na mudança de certas estruturas" (HOLLIDAY, 2006, p. 34). 
Assim, a presente sistematização pode ser considerada como um processo produtor de conhecimentos a partir da conceitualização da prática e da reconstrução ordenada da experiência que está posta em tela, possibilitando interpretações críticas sobre a dinâmica trabalhada que podem motivar reflexões teóricas e trabalhos práticos.

A escolha de Arroio do Padre dentre os seis municípios que englobam tal projeto se justifica pelo fato de que se tem o intento de demonstrar que, mesmo onde $91,7 \%$ da economia agrícola municipal provém do cultivo de tabaco (IBGE, 2019b), é possível obterse avanços, ainda que em curto prazo de tempo (pouco mais de doze meses), no que diz respeito à promoção e conservação da agrobiodiversidade.

A abordagem metodológica proposta por Holliday (2006) é baseada em cinco tempos, quais sejam: (i) o ponto de partida, ou seja, a própria experiência; (ii) responder as perguntas iniciais: para que sistematizar? O que queremos sistematizar? Quais aspectos centrais dessa experiência interessa sistematizar? Quais fontes de informação e procedimentos vamos adotar?; (iii) recuperar o processo vivido; (iv) analisar e interpretar - a reflexão de fundo; e (v) comunicar as experiências e aprendizagens - o ponto de chegada.

Com base nessa proposta, parte-se do Tempo I através de um resgate histórico sobre o CAPA, desde sua criação até as características que fundamentam o seu trabalho. Também foi resgatado um breve histórico do projeto de ATER em tela, que permitiu, além da prestação dos serviços, a elaboração deste trabalho. Tais pontos foram concretizados na introdução desta exposição.

As repostas para as perguntas propostas no Tempo II estão delineadas na seção a seguir, onde é abordado o contexto no qual foi desenvolvida a experiência em tela. Já os Tempos III e IV, ou seja, a recuperação do processo vivido e a análise e interpretação dos resultados, estão reportados na quarta seção deste trabalho, onde são ressaltados os aspectos relativos às sementes e mudas crioulas e varietais e sua relação com o trabalho de extensão rural oferecido pelo CAPA. Por fim, o Tempo V se concretiza com a elaboração desta exposição e com as considerações finais possibilitadas, as quais estão apresentadas na última seção do texto.

\section{Contexto}

Atualmente, a área rural da Serra do Tapes no estado do Rio Grande do Sul, região onde está situado o município de Arroio do Padre, é constituída por unidades produtivas 
familiares de pequeno e médio porte, onde grande parte dos agricultores familiares está vinculada ao capital comercial e industrial, com maior representatividade nas produções de tabaco, pêssego e leite (SALAMONI; WASKIEVICZ, 2013).

A produção de tabaco ocupa um espaço significativo na agricultura familiar da Serra dos Tapes, sendo o Rio Grande do Sul o maior produtor de fumo em folha do Brasil (ATLAS SOCIOECONÔMICO DO RIO GRANDE DO SUL, 2019). Os municípios de Canguçu, São Lourenço do Sul, Turuçu, Pelotas e Arroio do Padre destacam-se, na região sul do estado, como os principais produtores desta cultura (GARCIA, 2012).

Na microrregião de Pelotas, de acordo com dados da Pesquisa Agrícola Municipal (IBGE, 2019a), em 2015 foram produzidas 67,5 mil toneladas de tabaco. Recentemente, conforme dados da Associação dos Fumicultores do Brasil (AFUBRA) e do Sindicato Interestadual da Indústria do Tabaco (SINDITABACO), na safra 2018/2019, o município de Canguçu foi considerado o maior produtor de tabaco do Brasil (SINDITABACO, 2019). As mesmas fontes apontam São Lourenço do Sul no terceiro posto do ranking nacional, além de outros municípios que integram a Serra dos Tapes dentre os 30 maiores produtores de tabaco no país. Economicamente, muitos destes municípios são dependentes desta cadeia produtiva, caracterizada por contratos de integração vertical entre as famílias agricultoras e o complexo agroindustrial do setor fumageiro.

A cultura do tabaco garante aos agricultores condições como mercado consolidado, assistência técnica, pacotes de insumos e venda garantida, que facilitam para o agricultor tanto o cultivo como a comercialização. A questão que aqui se coloca está relacionada com a dependência econômica dos municípios da região e, mais do que isso, sobre a ameaça à produção diversificada de alimentos pela agricultura familiar inserida nesse contexto.

Apesar do destaque para a produção de tabaco na região, sempre foi marcante nesse território a forte presença da produção diversificada de alimentos, característica intrínseca da cultura das agricultoras e agricultores familiares. Entretanto, para Pollnow et al. (2017), a expansão do cultivo de tabaco nessa região ameaça diretamente essa produção de alimentos, o modo de ser dos agricultores e sua saúde. Nesse último caso, isso se dá pelo alto emprego de agrotóxicos ou ainda pela intoxicação com nicotina durante o processo de colheita ${ }^{3}$.

Além da ameaça à produção de alimentos e à saúde das agricultoras e agricultores, um estudo realizado em outra grande região produtora de fumo, a Região do Vale do Rio

3 Essa intoxicação é conhecida como a Doença da Folha Verde (FIORI, 2015). 
Pardo, também no estado do Rio Grande do Sul, demonstrou, por exemplo, que a renda oriunda da produção de alimentos, como hortifrutigranjeiros, pode ser superior à renda obtida com a fumicultura (VARGAS; OLIVEIRA, 2012).

Neste contexto, o trabalho de ATER oferecido pelo CAPA e voltado à diversificação produtiva busca fortalecer a produção de alimentos com base na agroecologia e no robustecimento das organizações sociais vinculadas à agricultura familiar da região, especialmente cooperativas que possibilitam, entre outros aspectos, a comercialização da produção.

O município de Arroio do Padre, âmbito sobre o qual recai o foco desta sistematização, é essencialmente rural. A Fig. 2 disposta a seguir apresenta a pequena área urbana do município, completamente envolvida por unidades produtivas da agricultura familiar. Com área territorial de 124,3 km2 e 2.730 habitantes, 94\% da população vive no meio rural (NEVES, 2012).

Figura 2: Sede do município de Arroio do Padre.

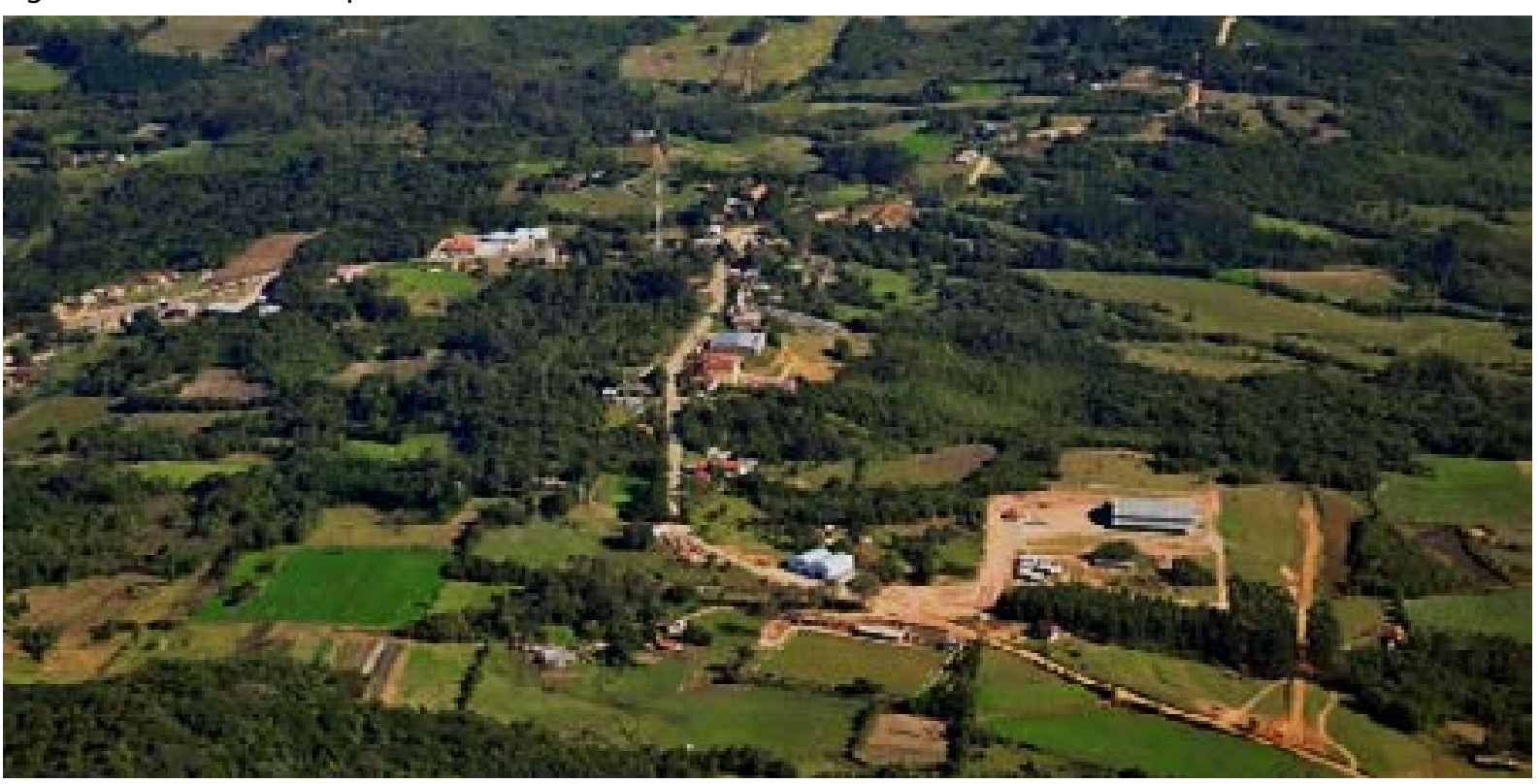

Fonte: Prefeitura Municipal de Arroio do Padre (2019).

Em 2015, conforme dados da Fundação de Economia e Estatística do Estado do Rio Grande do Sul (FEE, 2019), o Valor Agregado Bruto (VAB) ${ }^{4}$ do município foi composto

40 Valor Adicionado Bruto (VAB) é o valor que cada setor da economia (agropecuária, indústria e serviços) acresce ao valor final de tudo que foi produzido em uma região. O Produto Interno Bruto (PIB) é a soma dos VABs setoriais e dos impostos, e é a principal medida do tamanho total de uma economia (PESSOA; 2019). 
por $59,67 \%$ de contribuição do setor de serviços, 39,51\% pelo setor agropecuário e 3,53\% pelo setor industrial. Dentro do setor agropecuário, 91,7\% do valor da produção de lavouras anuais e permanentes é oriundo da produção de tabaco (IBGE, 2019b).

No ínterim de execução do referido projeto, foram realizadas algumas atividades junto ao público beneficiário, entre as quais: reuniões de socialização e mobilização; cadastro das famílias; diagnósticos das unidades familiares de produção agrária; planejamentos e projetos produtivos familiares; reuniões com os conselhos municipais de desenvolvimento rural; atividades técnicas de atendimento coletivo; e atividades de atendimento técnico individual.

Em Arroio do Padre, estas atividades foram realizadas envolvendo um público beneficiário direto de 80 famílias distribuídas em nove localidades do município. Logo no início de execução do projeto, principalmente durante a aplicação dos diagnósticos das unidades familiares de produção agrária, pôde-se perceber o pouco incentivo que se tinha no município para a utilização de sementes e mudas crioulas e varietais. Além dos grupos ecológicos já existentes, poucas famílias conheciam ou sabiam mencionar, por exemplo, qual a variedade de feijão que cultivavam. Em alguns casos, foi referido inclusive uma marca comercial de feijão, comumente encontrada em supermercados, como sendo uma variedade. No caso do milho, a grande maioria das famílias tem cultivado variedades híbridas e/ou transgênicas.

Apesar disso, estava presente na memória das famílias as variedades crioulas de milho e feijão que foram cultivadas em um passado não muito distante, cerca de uma geração pretérita. Em entrevista concedida a estudantes de pós-graduação da Universidade Federal de Pelotas (UFPel), o técnico responsável pelas atividades do projeto no município se referiu à essa memória das famílias nos seguintes termos:

\footnotetext{
E aí, começamos o contato com as famílias, fazendo os cadastros, conhecendo as pessoas, perguntando e tal. A gente começou então a colocar no debate com as famílias, com cada família, nas reuniões também, a questão das sementes, da diversificação. E pra minha surpresa, essa aceitação, essa entrada foi melhor... bem mais do que eu imaginava. Porque aí quando falava semente crioula com a maioria das famílias, vinha uma memória... do pai, muitas vezes, se é mais velho, da própria pessoa ali, do milho crioulo na região. Então a região tinha um milho crioulo, que circulava aqui. ${ }^{5}$
}

$5 \quad$ Informação oral fornecida pelo interlocutor MM, extensionista rural responsável por levar a cabo o referido projeto em Arroio do Padre, em entrevista realizada no dia 04 de dezembro de 2019. 
A partir desse resgate, foi possível estabelecer com as famílias estratégias de busca, distribuição, trocas e até mesmo comercialização de sementes e mudas crioulas e varietais. Assim, alcançaram-se alguns resultados bastante interessantes sob o ponto de vista da promoção do uso de materiais genéticos da agrobiodiversidade local. Estes resultados estão expostos na sequência.

\section{Resultados}

Conforme apresentado, com vistas à diversificação produtiva em áreas cultivadas com tabaco, o CAPA oferece um serviço de ATER fundamentado nas premissas da agroecologia. No município gaúcho de Arroio do Padre, com base nas demandas levantadas pelo público beneficiário do projeto em tela, buscou-se promover o uso sementes e mudas crioulas e varietais.

No caso das sementes, destaca-se o trabalho com as seguintes espécies: milho, feijão e cebola.

Em relação a sementes crioulas e varietais de milho, foi comercializado um total de $270 \mathrm{~kg}$ de sete variedades diferentes para 29 famílias. As variedades comercializadas foram: AL30, Argentino, Brasino, Caiano Rajado, Farináceo Branco, Pipoca Vermelha e SCS 155 Catarina. Essas variedades foram adquiridas da Cooperativa União (sediada no município vizinho de Canguçu/RS) e do assentamento de reforma agrária Santa Inácia, do município gaúcho de Pinheiro Machado.

Ainda sobre o milho, é importante notar os relatos que vêm das famílias agricultoras sobre o uso de materiais transgênicos na alimentação animal. Conforme o mesmo interlocutor mencionado anteriormente,

Nos ajuda nesse debate a questão do transgênico, que $90 \%$ deles, cada dez, nove dizem que elas não gostam de comer, galinha não gosta de comer. Ou se come, não sustenta. E essa semana eu escutei mais um relato que a silagem do milho transgênico, que teria ocasionado morte de animais. Então esse relato, não para de vim. Então, nos ajuda... Então o pessoal já cria uma aversão ao transgênico e a gente entra, né, com materiais bons. ${ }^{6}$

No que diz respeito a sementes de feijão, foram distribuídas, sem custo, 22 variedades, totalizando $70 \mathrm{~kg}$ de sementes para 33 famílias. As variedades foram: Amendoim, Azulão, 6 Informação oral fornecida pelo interlocutor MM, extensionista rural responsável por levar a cabo o referido projeto em Arroio do Padre, em entrevista realizada no dia 04 de dezembro de 2019. 
Branquinho, BRS Expedito, Carioca Pintado, Carioca Vermelho, Dega, Enxofre, Fepagro 26, Guabiju, Guapo Brilhante, Iraí, Manteiga, Milico, Mocotó, Mourinho, Pinhão, Pinheiro, Pitanga, Pitanguinha, Tupim e Taura. Algumas delas estão retratadas na imagem a seguir (Fig. 3).

Figura 3: Variedades de feijão distribuídas para 33 famílias.

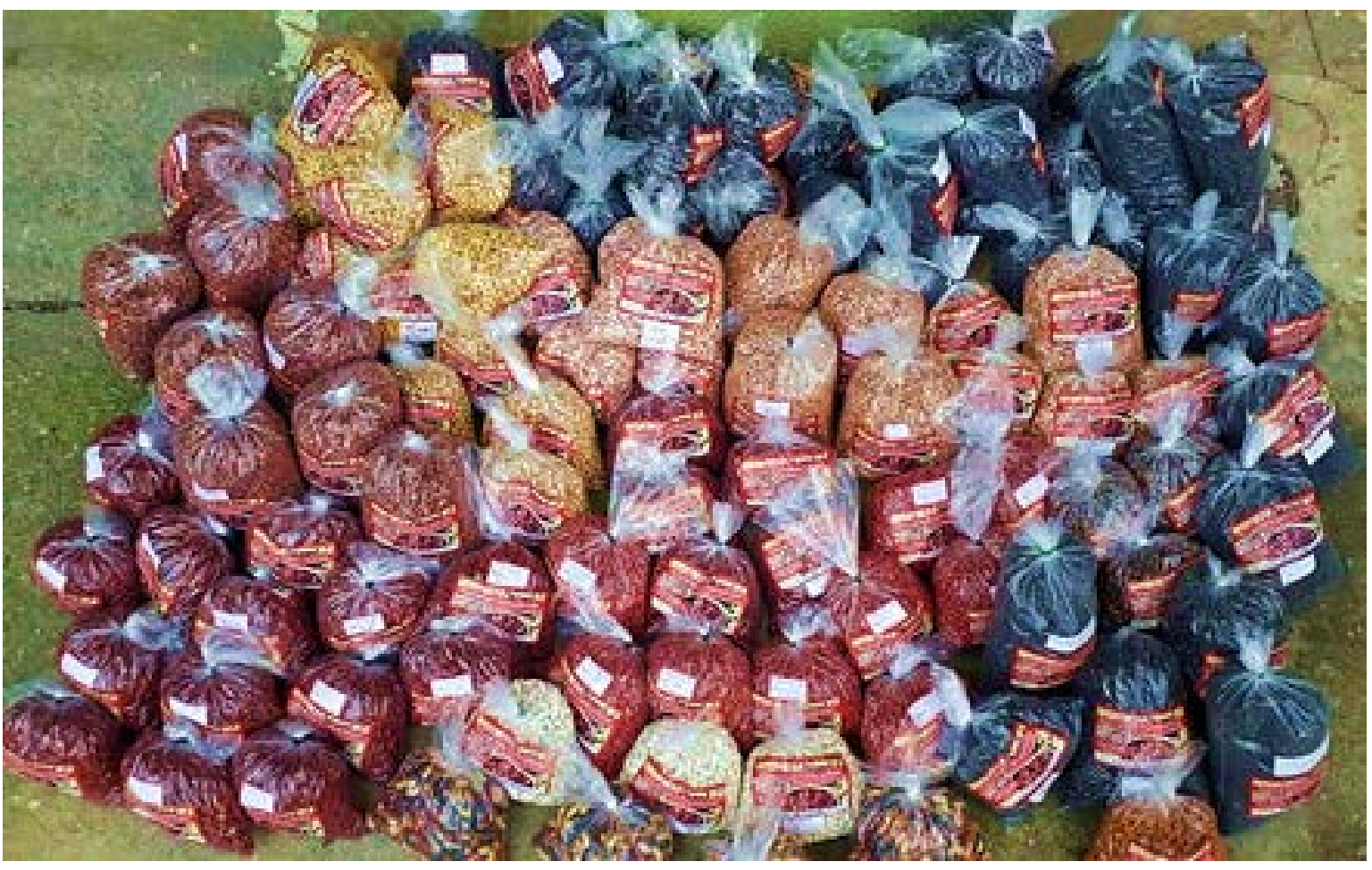

Fonte: Acervo dos autores.

Ressalta-se que estas variedades foram distribuídas a partir da construção de um programa do que foi chamado institucionalmente de "troca-troca" de feijão. Ou seja, em caso de boa colheita, cada família deverá devolver um volume três vezes maior do que recebeu gratuitamente, para que assim seja incrementado o estoque de sementes e um maior número de famílias possa ser beneficiado nas safras subsequentes. Nosso interlocutor se referiu a essa ação nos seguintes termos:

Então tu pegou $1 \mathrm{~kg}$, tu vai me devolver 3. Quem pegou 2 vai devolver 6. A gente fez um "troca-troca", sem custo pros agricultores. O compromisso dele é devolver a semente. Por quê? Porque ele assume um compromisso... a gente não tá obrigando a plantar, mas se quiser, devolve 3 pra 1, pra gente ter mais semente pra outros agricultores do Arroio do Padre e pra outros, a ideia é expandir.?

7 Informação oral fornecida pelo interlocutor MM, extensionista rural responsável por levar a cabo o referido projeto em Arroio do Padre, em entrevista realizada no dia 04 de dezembro de 2019. 
A Fig. 4 retrata um bom exemplo de diversificação produtiva, onde uma das lavouras de feijão implantada no município está localizada ao lado de uma lavoura de tabaco.

Figura 4: Lavoura de feijão implantada ao lado de uma lavoura de fumo.

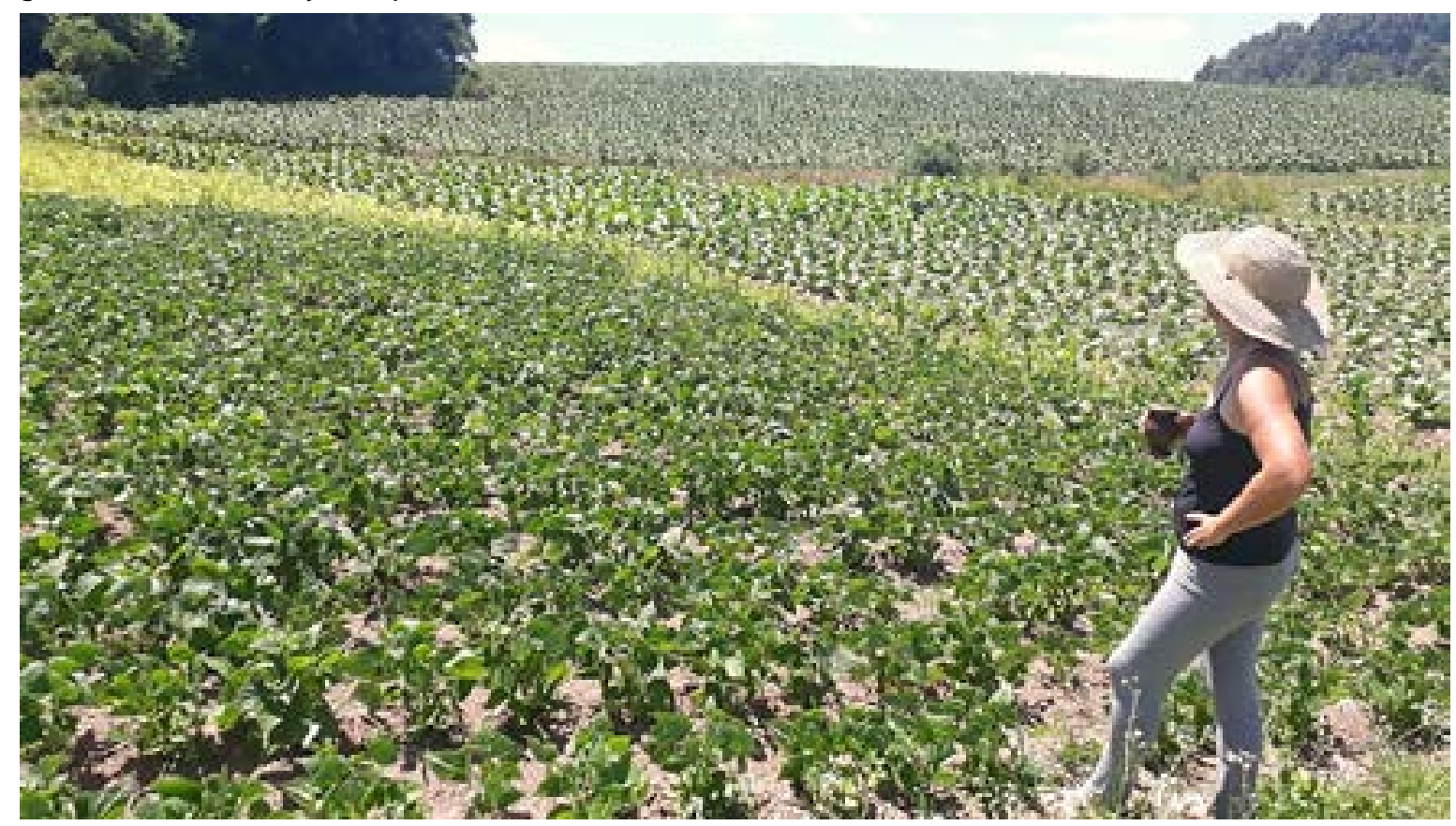

Fonte: Acervo dos autores.

Além disso, através de uma parceria com a Embrapa Clima Temperado8, foi implantada no município uma Unidade Demonstrativa Pedagógica (popularmente chamado "parcelão"), com 14 variedades de feijão doadas pela instituição. Tal metodologia poderá, além de promover o cultivo e consumo destas variedades entre as famílias, indicar quais delas melhor adaptam-se às condições microclimáticas e edáficas do município.

Em relação à cebola, foram comercializados $2 \mathrm{~kg}$ de sementes da variedade Juporanga para sete famílias, as quais adquiriram a semente com objetivo de comercializar a produção. A semente foi adquirida da Bionatur Sementes Agroecológicas ${ }^{\circ}$. As famílias relataram a satisfação com o estabelecimento das lavouras, com o desempenho e adaptação que a variedade demonstrou e com os resultados da colheita. A imagem a seguir (Fig. 5) retrata o estabelecimento de uma destas lavouras.

8 Ficam registrados aqui agradecimentos ao pesquisador Dr. Irajá Ferreira Antunes e ao seu grupo de trabalho.

9 Ver, a propósito Bionatur (2021). 
Figura 5: Estabelecimento de uma das lavouras de cebola variedade Juporanga no município de Arroio do Padre.

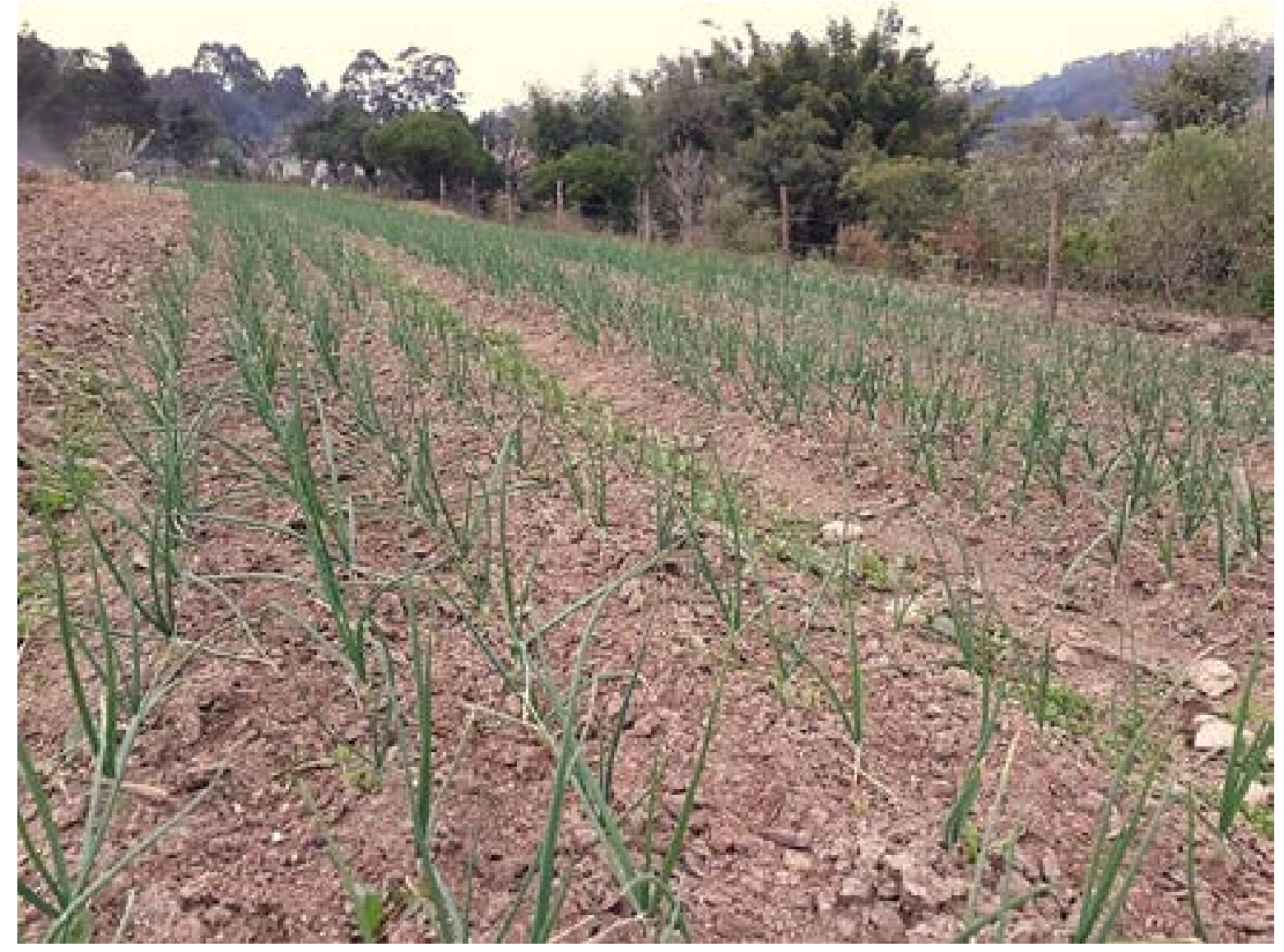

Fonte: Ac ervo dos autores.

No que diz respeito às mudas, trabalhou-se essencialmente com duas espécies: batata-doce roxa e abacaxi. As mudas de batata-doce foram doadas por uma família do próprio município beneficiária do projeto. 14 famílias receberam um total de 140 mudas (Fig. 6), as quais constituir-se-ão em matrizeiros para multiplicação nas próximas safras e consequente incremento na produção de batata-doce, utilizada em grande medida para soberania e segurança alimentar das famílias e para alimentação animal. 
Figura 6: Mudas de batata-doce roxa doadas às famílias.

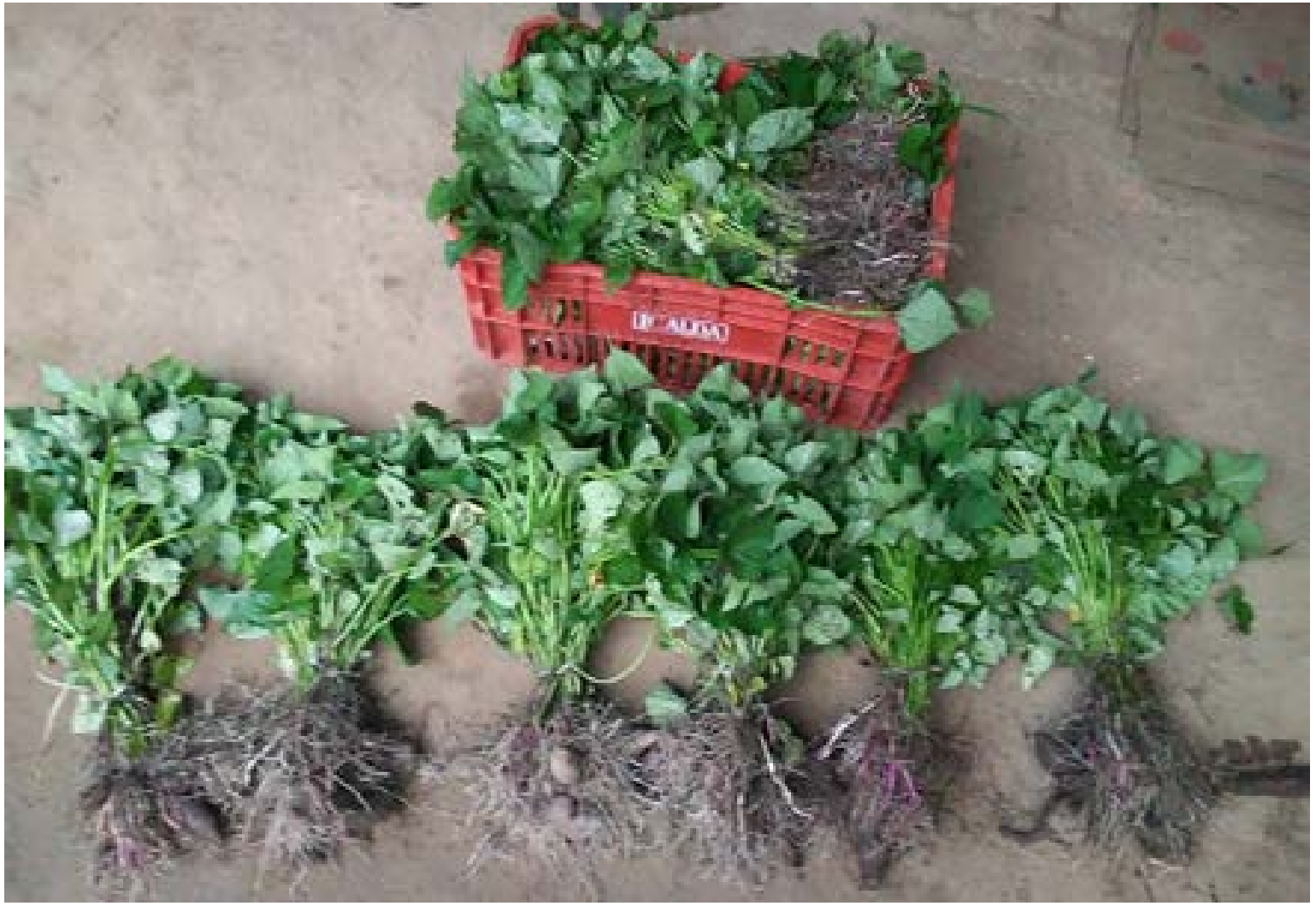

Fonte: Acervo CAPA.

Já no caso do abacaxi, as mudas foram oriundas do município vizinho de Turuçu (que também faz parte do referido projeto de ATER). A família turuçuense (representada na Fig. 7 pela avó e pelo neto ${ }^{10}$ ) comercializou na safra 2018/2019 quase duas toneladas de abacaxi, o qual está perfeitamente adaptado ao microclima local há quase 30 anos. Logo surgiu o interesse por parte de diversas famílias agricultoras de Arroio do Padre em adquirir mudas. Assim, 19 famílias adquiriram 280 mudas, gerando uma renda extra para a família de Turuçu. O técnico atuante no município de Arroio do Padre explicou que:

Fora a questão das sementes aí, a gente até abacaxi andamos distribuindo mudas. Lá em Turuçu, um casal de agricultores com mais de 80 anos lá que produz abacaxi há 30 anos. [...] Porque tem uma situação tal ali que não cai geada. E aí o colega esse passou, ela disse que tinha muda pra vender, eu ofereci no Arroio do Padre pro pessoal. Resumindo deu umas 200, quase 300 mudas de abacaxi. Inclusive tem três que já vão produzir abacaxi esse ano. Plantaram esse ano e já tá com abacaxi. ${ }^{11}$

10 Autorização concedida verbalmente para uso da imagem.

11 Informação oral fornecida pelo interlocutor MM, extensionista rural responsável por levar a cabo o referido projeto em Arroio do Padre, em entrevista realizada no dia 04 de dezembro de 2019. 
Figura 7: Família de Turuçu e sua área de produção de abacaxis.

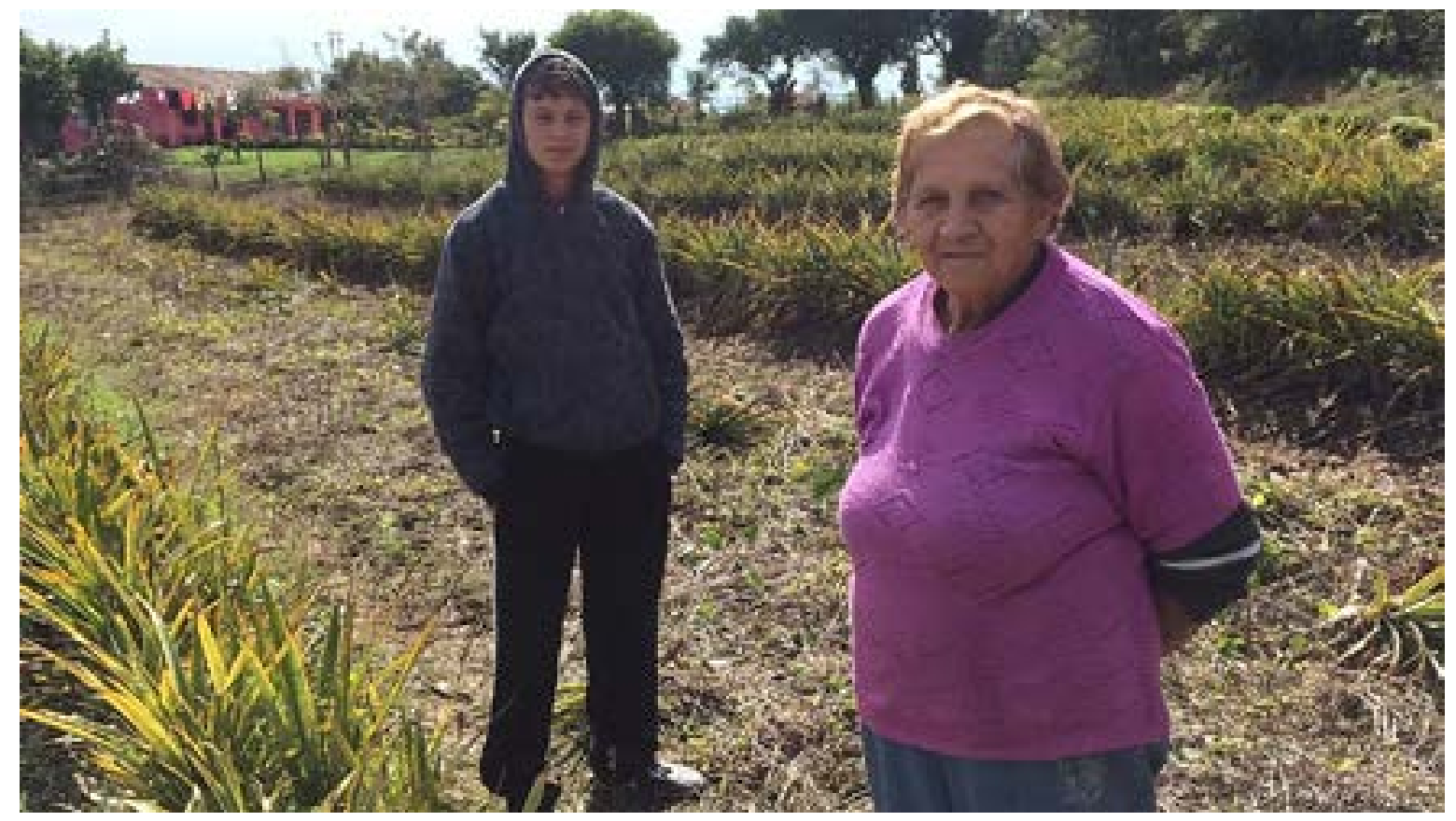

Fonte: Acervo CAPA.

Descrita a experiência a apresentados os seus resultados, podemos traçar algumas considerações finais sobre esse trabalho, as quais estão expostas na sequência.

\section{Considerações Finais}

Com base no que foi apresentado nesta sistematização, pode-se depreender sobre a importância das pessoas e das instituições para a conservação da agrobiodiversidade, incluindo as entidades prestadoras de serviços de ATER. Nesse sentido, é primordial que esse serviço seja diverso, forte e comprometido com as premissas da sustentabilidade e, mais do que isso, com a agroecologia.

Neste trabalho, foi relatada a experiência do CAPA no município de Arroio do Padre/RS, na prestação de serviços de ATER com foco na diversificação produtiva em áreas cultivadas com tabaco e com base na agroecologia. Nesse contexto, foi possível a distribuição, troca e/ou comercialização de sementes e mudas crioulas e varietais de milho, feijão, cebola, batata-doce e abacaxi para cerca de 80 famílias, contribuindo para a conservação da agrobiodiversidade. Mais do que fonte de renda para as famílias, incluindo aquelas que forneceram as sementes e mudas, experiências como esta contribuem para a soberania e segurança alimentar e nutricional. Em última análise, demonstra que existem 
outras possibilidades de manejo dos agroecossistemas e de formas de produção para além daquelas que comumente encontramos preconizadas na prestação de serviços convencionais de ATER.

\section{Referências}

ANATER. Chamadas públicas. CHAMADA PÚBLICA No 007_2018_Programa Nacional de Diversificação de Áreas Cultivadas com Tabaco (PNDACT). 2018. Disponível em: <http://www.anater.org/index.php/chamadapublica/>. Acesso em julho de 2021.

ATLAS SOCIOECONÔMICO DO RIO GRANDE DO SUL - 4a Ed. Porto Alegre, 2019. Disponível em: <https:// atlassocioeconomico.rs.gov.br/fumo> Acesso em julho 2019.

BIONATUR. Bionatur Sementes Agroecológicas. Disponível em: <https://www.bionatursementes.bio.br/>. Acesso em julho de 2021.

CAPA. Histórico - Pelotas. Disponível em: <https://capa.org.br/historico-pelotas/>. Acesso em novembro de 2019a.

CAPA. Atuação - Pelotas. Disponível em: <https://capa.org.br/atuacao-pelotas/>. Acesso em novembro de 2019b.

FEE. PIB dos municípios do RS em 2015. Disponível em: <https://www.fee.rs.gov.br/indicadores/pib-rs/ municipal/destaques/>. Acesso em novembro de 2019.

FIORI, N. S. Asma, tabagismo e absorção de nicotina em fumicultores do município de São Lourenço do Sul, RS. 2015. Tese (Doutorado em Epidemiologia) - Programa de Pós-Graduação em Epidemiologia da Universidade Federal de Pelotas, Pelotas, 2015.

GARCIA, Á. A. As exportações gaúchas em 2011. Indicadores Econômicos FEE, v. 39, n. 4, p. 57-67, 2012.

HOLLIDAY, O. J. Para sistematizar experiências. Trad. RESENDE, M. V. Série Monitoramento e Avaliação. Brasília: MMA, p. 128, 2006.

IBGE. Censo Agropecuário 2006 - características dos estabelecimentos. Disponível em: <https://ww2.ibge.gov. $\mathrm{br} /$ home/estatistica/economia/agropecuaria/censoagro/2006_segunda_apuracao/default_tab_munic_xls. shtm>. Acesso em abril de 2019a.

IBGE - Pesquisa Agrícola Municipal. Tabela 5457. Disponível em: <https://sidra.ibge.gov.br/tabela/5457>. Acesso em outubro de 2019b.

NEVES, E. H. das. Análise da degradação ambiental da Bacia Hidrográfica do Arroio Pelotas-RS, através do diagnóstico físico-conservacionista (DFC). 2012. Dissertação (Mestrado em Geografia) - Programa de PósGraduação em Geografia da Universidade Federal do Rio Grande do Sul, Porto Alegre, 2012.

PESSOA, M. L. (Org.). PIB e VAB do RS. In: _. Atlas FEE. Porto Alegre: FEE, 2017. Disponível em: http://atlas.fee. tche.br/rio-grande-do-sul/economia/pib-vab-do-rs/. Acesso em maio de 2019.

POLLNOW, G. E.; MARTINEZ, E. A.; SURITA, R. Diversificação produtiva e econômica em áreas cultivadas com tabaco na Zona Sul do Rio Grande do Sul (RS). In: II SIMPÓSIO BRASILEIRO DE DESENVOLVIMENTO TERRITORIAL SUSTENTÁVEL, 1., 2017. Matinhos. Anais... Matinhos: Universidade Federal do Paraná, 2017, p. 1093-1098. 
PREFEITURA MUNICIPAL DE ARROIO DO PADRE. PEC - Proposta de Emenda... Disponível em: <https://www. arroiodopadre.rs.gov.br/portal/noticias/0/3/796/PEC----Proposta-de-Emenda-Constitucional>. Acesso em dezembro de 2019.

SALAMONI, G.; WASKIEVICZ, C. A. Serra dos Tapes: espaço, sociedade e natureza. Tessituras: Revista de Antropologia e Arqueologia, v. 1, n. 1, p. 73-100, 2013.

SINDITABACO. Infográficos. Disponível em: <http://www.sinditabaco.com.br/sobre-o-setor/infograficos/>. Acesso em dezembro de 2019.

VARGAS, M. A.; OLIVEIRA, B. F. Estratégias de Diversificação em Áreas de cultivo de tabaco no Vale do Rio Pardo: uma análise comparativa. RESR, Piracicaba -SP, vol. 50, nº 1, p. 175-192, 2012. 